Revista Eletrônica do Mestrado em Educação Ambiental

Programa de Pós-Graduação em Educação Ambienta1

\title{
Redes Colaborativas Interorganizacionais no Projeto 'De Lixo A Bicho' do Instituto Federal de Santa Catarina - Campus de Itajaí
}

\author{
Graciane Regina Pereira ${ }^{1}$ \\ Instituto Federal de Santa Catarina, Campus Gaspar \\ ORCID: http://orcid.org/0000-0002-8266-4382 \\ Rose Fernandes de Souza ${ }^{2}$ \\ Instituto Federal de Santa Catarina, Campus Itajaí \\ ORCID: https://orcid.org/0000-0002-9221-6348
}

\begin{abstract}
Resumo: A educação ambiental tem um papel fundamental na construção de uma sociedade mais responsável, principalmente quando as organizações atuam em forma de redes colaborativas. $\mathrm{O}$ trabalho analisou as relações colaborativas entre os atores sociais que integram o projeto de extensão 'De lixo a bicho' realizado pelo Instituto Federal de Santa Catarina - Campus Itajaí. O trabalho é uma pesquisa aplicada, descritiva, de análise quanti-qualitativa, que utilizou como instrumento um questionário eletrônico. Os resultados mostraram que existe uma relação de colaboratividade entre os participantes da rede do projeto e que há contribuição nas práticas sustentáveis. Todavia, existe a necessidade de reforçar a identidade de rede, aproximando os participantes de todas as etapas do projeto, e realizar momentos formativos, visando o fortalecimento da rede.
\end{abstract}

Palavras-chave: Sustentabilidade; Educação Ambiental; Redes colaborativas.

\section{Redes Colaborativas Interorganizacionales en el Proyecto 'Basura A Animal' del Instituto Federal de Santa Catarina - Campus de Itajaí}

Resumen: La educación ambiental tiene un papel fundamental en la construcción de una sociedad más responsable, especialmente cuando las organizaciones operan en forma de redes de colaboración. El trabajo analizó las relaciones de colaboración entre los actores sociales que forman parte del proyecto de extensión "De basura a animal" llevado a cabo por el Instituto Federal

\footnotetext{
${ }^{1}$ Doutora em Engenharia Ambiental pela Universidade Federal de Santa Catarina (UFSC). Professora na área ambiental do Instituto Federal de Santa Catarina (IFSC), Câmpus Gaspar, Gaspar - SC, Brasil. E-mail: gracianerp@ifsc.edu.br

2 Tecnóloga em Processos Gerenciais pelo Instituto Federal de Santa Catarina (IFSC), Câmpus Gaspar. Técnica administrativa no Instituto Federal de Santa Catarina (IFSC), Câmpus Itajaí, Itajaí - SC. E-mail: rose.fernandes@ifsc.edu.br
} 
de Santa Catarina - Campus Itajaí. El trabajo es una investigación aplicada, descriptiva, de análisis cuantitativo y cualitativo, que utilizó un cuestionario electrónico como instrumento. Los resultados mostraron que existe una relación de colaboración entre los participantes en la red del proyecto y que hay una contribución a las prácticas sostenibles. Sin embargo, existe la necesidad de reforzar la identidad de la red, acercando a los participantes a todas las etapas del proyecto, y llevar a cabo momentos de capacitación, con el objetivo de fortalecer la red.

Palabras clave: Sostenibilidad; Educación ambiental; Redes colaborativas.

\title{
Inter-Organizational Collaborative Networks in the 'Garbage To Animal' Project of the Federal Institute Of Santa Catarina - Campus De Itajaí
}

\begin{abstract}
Environmental education has a fundamental role in building a more responsible society, especially when organizations operate in the form of collaborative networks. The work analyzed the collaborative relations between the social actors that are part of the extension project 'From garbage to animal' carried out by the Federal Institute of Santa Catarina - Campus Itajaí. The work is an applied, descriptive research, of quantitative and qualitative analysis, which used an electronic questionnaire as an instrument. The results showed that there is a collaborative relationship between the participants in the project network and that there is a contribution to sustainable practices. However, there is a need to reinforce the network identity, bringing participants closer to all stages of the project, and to conduct training moments, aiming at strengthening the network.

Key words: Sustainability; Environmental education; Colaborative networks.
\end{abstract}

\section{Introdução}

O desenvolvimento sustentável de um país depende em grande parte do fortalecimento das suas organizações. Essas organizações têm buscado meios eficientes e eficazes de gerir seus recursos de maneira sustentável, pois o mundo vive um verdadeiro colapso ambiental devido ao desequilíbrio ecológico desencadeado ao longo das últimas décadas. A degradação do meio ambiente e os impactos negativos gerados pela intervenção do homem na natureza e a geração de resíduos, tem levado profissionais da educação, movimentos sociais, ativistas ambientais, gestores públicos, organizações e demais membros da sociedade, a refletir em como conscientizar a população sobre a importância de desenvolver práticas sustentáveis (MAGOZO, 2005), questionando modelos insustentáveis vigentes.

Nesse sentido, a educação ambiental tem um papel fundamental na construção de uma sociedade mais consciente, uma vez que visa trabalhar de maneira didáticopedagógica e com uma abordagem crítica e reflexiva, estimulando que o sujeito, percebase como responsável e partícipe do processo de proteção do ambiente em que vive, evidenciando à sociedade, os benefícios e transformações advindos de práticas mais sustentáveis (PELICIONI; PHILIPPI JUNIOR, 2005). Por conta das diferentes condições sociais e dos diferentes cenários, existem por consequência, diferentes formas de 
percepção e de atuação dos sujeitos neste processo, qualquer abordagem educativa tem de considerar estas especificidades.

Atrelada a essas práticas sustentáveis, pode-se citar as redes colaborativas interorganizacionais, as quais são o conjunto de três ou mais organizações que se unem por meio de uma aliança, em torno de algum propósito. Em uma rede colaborativa, os pontos (sujeitos envolvidos) e os elos (relação entre os membros), se interligam e estão conectados em prol de um objetivo comum (MARIANO; GUERRINI; REBELATTO, 2012).

As redes interorganizacionais colaborativas têm se tornado cada vez mais comuns, e as empresas têm continuamente percebido as vantagens obtidas com o estabelecimento de alianças (MARIANO; GUERRINI; REBELATTO, 2012). Pereira (2010) destaca que o trabalho em rede, promove e favorece a articulação com os setores produtivos e a sociedade.

Para descortinar as minúcias de uma rede, analisou-se as relações colaborativas dos atores que compõem o projeto de extensão 'De lixo a bicho' executado no Instituto Federal de Educação Ciência e Tecnologia de Santa Catarina (IFSC), Campus Itajaí, o qual desenvolve ações de educação ambiental. Para isso, os conceitos relacionados ao desenvolvimento sustentável e educação ambiental foram aprofundados, bem como sobre as redes colaborativas interorganizacionais. Entendendo a percepção que os participantes têm sobre a rede foi possível identificar a tipologia da rede colaborativa relacionada ao projeto 'De lixo a bicho'. Os resultados permitiram propor sugestões para o fortalecimento da rede.

\section{Desenvolvimento Sustentável e Educação Ambiental}

Mano, Pacheco e Bonelli (2005) ressaltam que nos tempos atuais, é evidente à humanidade que um dos objetivos do desenvolvimento econômico é gerar riqueza e conforto, muitas vezes à custa do esgotamento dos recursos naturais, indo assim de encontro às ações de preservação e proteção do meio ambiente. Assim sendo, faz-se necessário refletir urgentemente, em como desenvolver-se economicamente sem prejuízo ao meio ambiente. Essa deve ser a meta da civilização.

Dias (2011) aponta que o desenvolvimento sustentável orientado para as organizações aponta três importantes dimensões: a social, a econômica e a ambiental. Nesse contexto, no que tange ao viés econômico, as organizações precisam ser rentáveis, a fim de que seja gerado um retorno do capital investido; em termos sociais, a empresa deve 
buscar oferecer melhores condições de trabalho aos seus colaboradores; no que diz respeito à dimensão ambiental as organizações devem adotar uma postura responsável, buscando desenvolver uma cultura ambiental que adote posturas ecoeficientes em seus processos produtivos.

Barbieri e Silva (2011) discutem em seu trabalho a importância da expressão desenvolvimento sustentável, que é o desenvolvimento entendido como melhoria da qualidade de vida de todos os humanos, com justiça social e respeito às condições e características do meio ambiente, para que as futuras gerações possam prover suas subsistências com qualidade. Neste sentido, foram estabelecidos os Objetivos do Desenvolvimento Sustentável (ODS) da Agenda 2030 que, em síntese, constitui-se em um plano de ações colaborativas para fortalecer a qualidade de vida para todos. O Brasil, como um dos signatários dos ODS, vem incorporando-os em diversas políticas públicas, como também as demais organizações do país.

Adotar práticas sustentáveis, levando a sociedade a refletir criticamente sobre como desenvolver-se economicamente sem prejuízo ao meio ambiente deve ser o desafio de todo cidadão e organização. É preciso que as autoridades governamentais e gestores dos setores produtivos, tanto privados quanto públicos, fomentem uma mudança cultural profunda em suas práticas e que estas, por sua vez, perpassam os indivíduos levando-os a reordenar e repensar suas práticas e hábitos em prol da proteção do meio ambiente. Essa mudança é possível por meio da educação ambiental.

A Educação Ambiental é um processo que consiste em propiciar às pessoas uma compreensão crítica e global do ambiente, Pelicioni e Philippi Jr. (2005) destacam que refletir de maneira crítica sobre algo, deve por sua vez, conduzir o indivíduo a práxis, ou seja, ação-reflexão-ação. Seu conceito está intrinsecamente ligado a um processo que consiste em garantir um entendimento crítico e reflexivo da sociedade sobre os problemas ambientais, que por sua vez, predispõe o indivíduo às ações que geram mudanças profundas tanto de hábitos e costumes, quanto cultural.

O projeto 'De lixo a bicho' trabalha em forma de redes colaborativas ao fazer uso de resíduos de empresas parceiras locais para elaborar jogos educativos com viés socioambiental, atribuindo novas funcionalidades a materiais que iriam para o lixo. Para Mattos e Granato (2005) reutilizar nada mais é que aumentar o tempo de vida útil de resíduos que seriam descartados e atribuir a estes, novas funcionalidades. O projeto aborda aspectos da educação ambiental como instrumento de transformação do indivíduo e da coletividade. 


\section{Redes colaborativas}

Segundo Olivieri (2003) a palavra rede é bem antiga e, seu significado, se resume em um entrelaçamento de fios com o intuito de formar uma espécie de tecido. Com o tempo a palavra rede ganhou novos sentidos e levando em consideração seu aspecto histórico-social, redes são considerados sistemas organizacionais que têm a capacidade de integrar cidadãos e instituições de maneira democrática em torno de razões e causas comuns, que em suma, supõem uma ação colaborativa e participativa (OLIVIERI, 2003).

Rede seria um conjunto de pontos interligados de forma horizontal [...] um conjunto de nós e linhas organizado de forma não-hierárquica. Esse é um aspecto decisivo quando consideramos a rede como um padrão organizativo e um modo de operação de caráter emancipatório [...]. Num diagrama de qualquer rede, há necessariamente pontos e linhas. Os pontos representam as unidades que compõem a rede: pessoas, organizações, equipamentos, locais. As linhas representam as relações entre esses elementos [...] as linhas são mais importantes que os pontos num desenho de rede. Isso porque são as conexões que fazem uma rede [...]. A rede se exerce por meio da relação contínua das conexões. (MARINHO, 2003 p. 17-18).

Na figura 1(a) é possível perceber a relação existente entre os pontos por meio da ligação das linhas, possibilitando diversas conexões entre os atores sociais da rede. Tal conexão inexiste na figura 1(b), logo não configura uma rede, ou seja, a existência dos pontos por si só, não constituem uma rede quando não há ligação entre eles.

Figura 1. Modelo em rede (a) e modelo que não é rede (b).

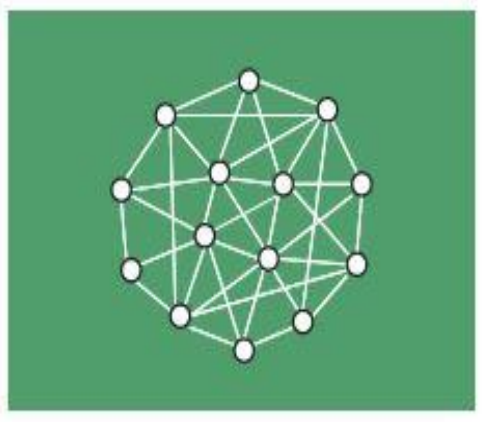

(a)

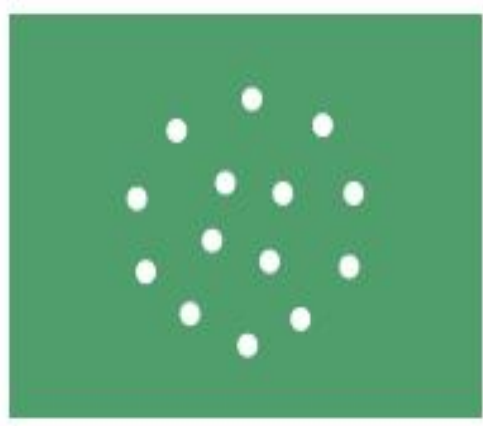

(b)

Fonte: Marinho (2003)

Kronemberg (2011) ressalta que o trabalho em rede se caracteriza pela formação de alianças estratégicas que congregam esforços para realizar ações conjuntas, no qual uma parte fortalece a outra. O trabalho em rede deve ser estimulado objetivando induzir e 
mobilizar os indivíduos a participarem das ações organizadas, pois sem a participação coletiva, ainda que o desenvolvimento ocorra, não será sustentável.

Segundo Fernandes (2008), um sistema em rede significa que seus participantes estejam ligados horizontalmente aos demais. Esta ligação realiza-se ou de maneira direta ou por meio dos que o rodeiam, no qual o trabalho coletivo visa um objetivo definido.

O trabalho em rede destaca-se justamente pela maneira como as relações entre os atores envolvidos ganham corpo e materializam-se no apoio a atividades de discussão e negociação de projetos, permitindo a integração e expansão conceitual dos envolvidos com o intuito de atingir um objetivo comum (PEREIRA, 2010).

A configuração em redes conduz resultados para além dos processos, rotinas estratégias e metas, de forma a criar medidas mitigadoras que minimizem os impactos que as atividades organizacionais possam causar ao ambiente, objetivando o desenvolvimento sustentável intra e interinstitucionais, e da comunidade em que está inserida (SHRIBERG, apud NAVARRO; SAMPAIO, 2012, não paginado).

Observa-se que uma rede tem a capacidade e o objetivo de integrar pessoas, instituições, comunidades em prol de um objetivo definido por meio de alianças estratégicas. Quanto maior for a relação entre os membros, mais forte essa rede será.

\section{Tipologias de rede}

Inojosa (1999) aponta que quanto ao foco de atuação as redes podem ser classificadas como redes de mercado e redes de compromisso social. As redes de mercado visam a potencialização dos parceiros, articulam-se na apropriação de bens ou serviços no qual as relações atendem os interesses do mercado. As redes de compromisso social têm seu foco em questões sociais, visam suprir a ausência do Estado no equacionamento de problemas sociais, demandam estratégias de mobilização para a obtenção de parcerias e a relação entre os membros se sustenta por uma visão comum a respeito da sociedade ou de certa questão social que demande uma ação solidária.

O Quadro 1, apresenta os tipos de redes com relação a dimensão: vertical, horizontal, formal e informal, descrevendo de que forma ou por quem estas redes são constituídas. 
Quadro 1. Dimensão tipologia de redes.

\begin{tabular}{|l|l|l|}
\hline $\begin{array}{c}\text { Tipos de } \\
\text { redes }\end{array}$ & \multicolumn{1}{|c|}{ Dimensão } & \multicolumn{1}{|c|}{ Descrição } \\
\hline Vertical & Hierárquica & $\begin{array}{l}\text { Essa configuração é utilizada, por exemplo, pelas grandes redes de } \\
\text { distribuição, que adotam a estratégia de redes verticais para estar mais } \\
\text { próximas do cliente, como ocorre com as grandes redes de distribuição } \\
\text { integrada }\end{array}$ \\
\hline Horizontal & Cooperativa & $\begin{array}{l}\text { São constituídas por empresas que guardam cada uma a sua independência, } \\
\text { mas optam por coordenar atividades específicas de maneira conjunta }\end{array}$ \\
\hline Formal & Contratual & $\begin{array}{l}\text { São formalizadas por meio de termos contratuais que estabelecem regras de } \\
\text { condutas entre os atores }\end{array}$ \\
\hline Informal & Conivência & $\begin{array}{l}\text { Permitem os encontros informais entre os atores sociais econômicos, que são } \\
\text { portadores de preocupações comuns }\end{array}$ \\
\hline
\end{tabular}

Fonte: Adaptado de Marcon e Moinet (2000 apud ALMEIDA, 2014).

No que diz respeito à tipologia quanto à relação entre os membros, as redes podem classificar-se em: subordinadas, tuteladas e autônomas.

Rede subordinada: os entes são parte de uma organização ou sistema; existe uma interdependência entre os objetivos; a articulação independe da vontade dos entes; há apenas um locus de controle. Rede tutelada: os entes têm autonomia mas articulam-se sob a égide de uma organização; a rede fica dependente da persistência dos propósitos do ente mobilizador; o qual tende a ficar como locus de controle. Rede autônoma: os entes são autônomos e articulam-se voluntariamente; pressupõe uma ideia-força mobilizadora; a rede é aberta e trabalha por pactuação; as identidades dos parceiros são preservadas e constrói-se uma identidade de rede; o controle é compartilhado (INOJOSA, 1999, p. 120).

Percebe-se a especificidade e dinâmica de um trabalho realizado em rede. O padrão não organizativo também contribui nesse processo uma vez que a não hierarquização permite que os membros que compõem a rede, trabalhem de forma independente, porém em prol de objetivos comuns. Uma rede interorganizacional pode ou não configurar-se como uma rede colaborativa, tudo dependerá das relações em que se apoiam os processos colaborativos entre as organizações (PEREIRA, 2010).

As redes são constituídas pelos seus Nós (sujeitos) e Elos (ligações).

As ligações entre os nós podem variar em duas dimensões; isto é, pode-se observar entre quais nós se realizam as ligações e também a densidade das relações sociais. A primeira dimensão se diferencia em dois tipos de ligações: uma refere-se às relações com organizações do mesmo setor ou com nós de uma indústria diferente; a outra parte do pressuposto de que existem ligações que podem ser mais fortes do que outras (CUNHA; PASSADOR; PASSADOR, 2011, não paginado).

Nesse sentido, torna-se possível caracterizar a estrutura de uma rede colaborativa a partir na análise de sua densidade ou fragmentação, ou seja, a estrutura dessa rede será fragmentada caso exista falhas estruturais resultantes da ausência ou pouca 
ligação/interação entre os membros da rede. Em contrapartida, sua característica estrutural será densa/compacta se a relação/ligação entre os atores sociais dessa rede for conexa, fortemente presente. De tal maneira que, densidade, é o nível global das ligações entre os indivíduos que compõem a rede e centralização, como o próprio nome denota, é a quantificação de até que ponto algumas organizações estão mais centralmente localizadas do que as demais organizações que compõem a rede, e assim quanto mais centralizada menos densa será (MARIANO; GUERRINO; REBELATTO, 2012).

\section{Metodologia}

No que diz respeito à tipologia técnica, a pesquisa classificou-se como aplicada. Para Souza, Fialho e Otani (2007), a pesquisa aplicada tem por objetivo produzir conhecimento para uma empregabilidade prática e direcionada à solução de problemas específicos, com vistas a atender demandas sociais.

Em relação às fontes de informação, fez-se uso da pesquisa bibliográfica que consiste em utilizar como fonte de coleta de dados, materiais publicados como livros, revistas, periódicos, dissertações, teses, etc. (SOUZA; FIALHO; OTANI, 2007). Quanto à abordagem em relação ao problema da pesquisa, foram utilizados métodos qualitativos e quantitativos, pois ao adotar a prática de combinar essas duas análises, a pesquisa passa a ter maior credibilidade. De tal maneira, é possível evitar o reducionismo por somente uma única opção de análise (OLIVEIRA, 2011).

Do ponto de vista de seus objetivos/fins, esta pesquisa foi descritiva, pois:

A pesquisa descritiva deseja conhecer a sua natureza, sua composição, processos que o constituem ou nele se realizam. [...]. O problema será anunciado em termos de indagar se um fenômeno acontece ou não, que variáveis o constituem, como classificá-lo, que semelhanças ou diferenças existem entre determinados fenômenos, etc. Os dados obtidos devem ser analisados e interpretados e podem ser qualitativos, utilizandose palavras para descrever o fenômeno, ou quantitativos, expressos mediante símbolos numéricos (RUDIO, 2015, p. 71).

Com o intuito de compreender a articulação entre os membros da rede colaborativa, realizou-se uma análise documental do projeto 'De lixo a bicho', de 2017 a 2019.

A característica da pesquisa documental é tomar como fonte de coleta de dados apenas documentos, escritos ou não, que constituem o que se denomina de fontes primárias. Estas podem ter sido feitas no momento 
em que o fato ou fenômeno ocorreu, ou depois (MARCONI; LAKATOS, 2017, p. 190).

Como procedimento técnico, se utilizou um questionário eletrônico aplicado aos atores sociais que compõem a rede colaborativa do projeto 'De lixo a bicho' (servidores, alunos bolsistas e voluntários, colaboradores externos, empresas, instituições de ensino pública e privada, instituição ambiental). Gil (2017) explica que o questionário pode ser definido com um meio de traduzir os objetivos específicos de determinada pesquisa com pontos bem redigidos. O questionário continha quinze questões fechadas e uma questão aberta. Utilizou-se em oito questões a escala de Likert, no qual são apresentadas escalas com cinco opções de respostas: 'Discordo totalmente'; 'Discordo parcialmente'; 'Concordo parcialmente'; 'Concordo totalmente'; 'Não concordo e nem discordo'.

O estudo utilizou a amostragem probabilística, que segundo Marconi e Lakatos (2017, p. 244) "baseia-se na escolha aleatória dos pesquisados, significando o aleatório que a seleção se faz de forma em que cada membro da população tenha a mesma probabilidade de ser escolhido". Como o número de integrantes varia constantemente, para determinação da amostra considerou-se como população os participantes da rede em 2019: 36 pessoas. A amostra foi de 24 membros participantes da rede, ou 66, 6\% da população. Em termos práticos, tal amostra representa $90 \%$ de confiabilidade da pesquisa e apresenta uma margem de erro de $9,8 \%$ para mais ou para menos.

A partir dessa perspectiva e, embasados no aporte teórico acerca de que, "apenas as amostragens probabilísticas oferecem a probabilidade de generalizar os resultados da população da amostra" (COOPER; SCHINDLER, 2016, p. 345), foram feitas as análises de resultados de uma forma geral, compreendendo a rede como um todo.

\section{Projeto 'De lixo a bicho' e suas redes colaborativas}

O projeto de extensão 'De lixo a bicho' é realizado no IFSC - Campus Itajaí desde 2016 foi idealizado a partir de atividades de ensino que objetivavam elaborar brinquedos com materiais (resíduos) que seriam descartados, em especial, resíduos têxteis. O projeto busca promover a transformação social a partir da educação, utilizando o lúdico como uma importante ferramenta de aprendizado (LIMA et al., 2019).

A rede colaborativa do projeto ganhou corpo estabelecendo parcerias com professores, técnicos administrativos em educação, alunos voluntários, empresas e instituições de ensino, que se identificaram e articularam-se em torno de um objetivo 
comum. Desde o início, o projeto articulou-se em rede colaborativa fomentando vivências e ações de educação socioambiental junto à comunidade por meio da utilização de materiais lúdicos residuais' (PEIXE, 2016). Atualmente o projeto conta com oito jogos adaptados (Figura 2). Os jogos apresentam conteúdos relacionados à sustentabilidade e fomentam discussão e reflexão acerca de temáticas diversas.

Figura 2. Jogos do projeto 'De lixo a bicho'

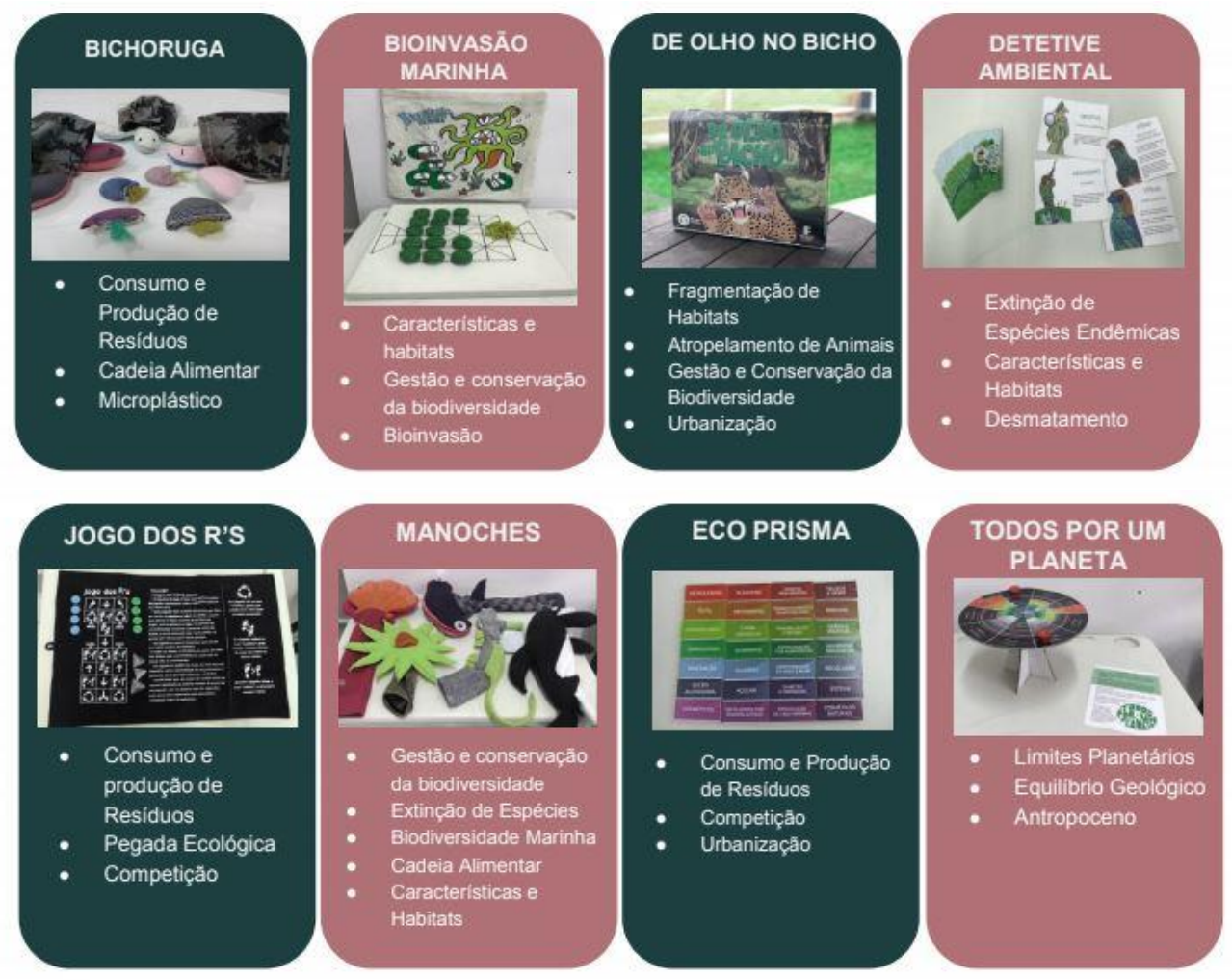

Fonte: Acervo do projeto 'De lixo a bicho’ (2019).

O primeiro brinquedo produzido pela equipe do projeto recebeu o nome de 'bichoruga', o qual é uma adaptação do jogo das três Marias originalmente confeccionado com pedras ou saquinhos de arroz. A 'bichoruga', é produzida com tecidos, fios (resíduos doados pelas empresas) e conchas. O brinquedo recebe esse o nome de bichoruga porque seu desenho final é de uma tartaruga, e bicho, provém no nome do projeto 'De lixo a bicho' uma vez que as ações do projeto se relacionam com questões socioambientais. Na Figura 2 (primeira imagem superior esquerda) verifica-se o jogo 'bichoruga'.

Analisando a composição da rede colaborativa do projeto, percebeu-se que há alterações dos atores ao longo do tempo, pela própria dinâmica de uma rede, na qual entram e saem atores durante o processo, por exemplo, os alunos. Cada parceiro/ator social da rede colaborativa do projeto exerce um papel: a) Empresas parceiras: doam matéria- 
prima (resíduos limpos) para a confecção dos brinquedos; b) Instituições de ensino públicas e privadas e instituição ambiental: demandam as ações do projeto, solicitando oficinas em seus espaços, ou contribuindo no designer de alguns jogos e, muitas vezes tornam-se multiplicadores das ações recebidas; c) Coordenadores (as) do projeto: tem um papel mais estratégico e gerencial, pois cumprem a função buscar fomento e designar de forma participativa e democrática as responsabilidades; d) Voluntários externos articulamse com os membros da equipe executora e com as empresas e instituições, participando além de atuar como oficineiros; e) Membros da equipe executora: trabalham no desenvolvimento dos jogos e nas estratégias educativas.

Com relação aos participantes da rede, $71 \%$ identificaram-se como coordenadores e membros da equipe executora (servidores, alunos e voluntários externos). Os outros $25 \%$ correspondem às empresas e instituições parceiras. Um participante não se identificou.

Identificados os membros da rede colaborativa, se levantou o tempo de atuação na rede. Dos vinte quatro (24) respondentes, 33,3 \% atuam no projeto 'há mais de dois anos'. Como os documentos analisados correspondem a três anos de execução do projeto, esse quantitativo é significativo, e mostra o estreitamento das relações entre os participantes, já o percentual de quem está no projeto 'há menos de seis meses' é de apenas $8,3 \%$.

As questões seguintes visavam compreender se os participantes têm o entendimento que a colaboratividade no planejamento e desenvolvimento das ações, podem convergir em práticas ambientais mais conscientes e sustentáveis e que, por conseguinte, contribuir com desenvolvimento humano, acadêmico, profissional e social de seus participantes. Dessa forma, os respondentes foram questionados se o projeto 'De lixo a bicho' pode contribuir na construção de uma sociedade mais consciente no que se refere às questões ambientais. Do total, apenas um concordou parcialmente com a afirmativa, os demais concordaram totalmente $(96 \%)$.

As questões ambientais estão relacionadas à construção e evolução da educação ambiental. Pelicioni e Philippi Jr. (2005) falam de uma educação ambiental que garanta uma ação transformadora. Para isso, faz-se necessário adquirir conhecimentos e habilidades formadas a partir de valores éticos que garantam posturas mais sustentáveis. A próxima questão afirmava que 'desenvolver um trabalho colaborativo no projeto 'De lixo a bicho' contribui para um desenvolvimento local mais sustentável'. Como resultado, quase $80 \%$ optou por 'concordo totalmente', o que permite afirmar que o projeto 'De lixo a bicho’ contribui para um desenvolvimento local mais sustentável. 
O projeto 'De lixo a bicho' apresenta como uma de suas características, a importância da educação ambiental e entende a relevância de trabalhar essa temática com os acadêmicos e com a comunidade externa, por meio de parcerias. Tal processo, deve permitir que o ser humano não apenas identifique e reflita sobre os problemas que permeiam a temática ambiental, mas que sobretudo esse processo seja dialético conduzindo a uma práxis que o leve a agir sobre as causas e efeitos que giram em torno dos problemas ambientais, buscando meios e instrumentos de superação cada vez mais sustentáveis (CASTRO; CANHEDO JUNIOR, 2005). Assim, buscou-se as respostas para a afirmação: 'a participação no projeto 'De lixo a bicho' contribui em minha formação acadêmica, profissional, humana e social' e $87,5 \%$ respondeu 'concordo totalmente'.

Identificou-se a tipologia de rede considerando a relação entre os membros, segundo Inojosa (1999) estas podem ser classificadas em redes: subordinadas, tuteladas e autônomas. O autor aponta que, em redes subordinadas há apenas um locus de controle, a partir desse contexto buscou compreender se este local de controle existe ou se os processos de planejamento e decisão realizam-se de forma colaborativa, por meio da afirmação: 'minha participação no planejamento e decisão das ações desta rede colaborativa dentro do projeto 'De lixo a bicho' são satisfatórias, ou seja, participo plenamente desses momentos'. Percebeu-se que 41,7 \%, 'concorda totalmente' com a afirmação. Embora esse número seja próximo de $50 \%$ dos membros, é importante considerar que mais de 37,5\% responderam 'concordo parcialmente'. Considerando ainda que quatro pessoas $(16,7 \%)$, optaram por 'não concordo e nem discordo' e que uma pessoa respondeu 'discordo parcialmente', compreende-se que nem todos os membros sentem-se totalmente participantes dos processos de planejamento e tomada de decisão. Tal análise, pode revelar uma leve fragilidade da rede. Os dados permitem ainda, afirmar que esta não é uma rede subordinada tendo em vista que ninguém respondeu 'discordo totalmente'.

A partir dessa análise, ainda se fez necessário definir a tipologia de rede em relação aos membros que a compõem, conforme Quadro 2.

Quadro 2. Classificação tipológica da rede quanto a relação entre os membros.

\begin{tabular}{|l|c|}
\hline Alternativas & Participantes \\
\hline Rede subordinada & - \\
\hline Rede tutelada & $16,4 \%$ \\
\hline Rede autônoma & $54,2 \%$ \\
\hline Nenhuma das alternativas contempla a tipologia quanto a relação existente na rede & $4,2 \%$ \\
\hline Não sei opinar. & $25 \%$ \\
\hline
\end{tabular}

Fonte: Elaborado pelas autoras (2019). 
Embora o número dos que não souberam opinar seja significativo, é preciso considerar que nenhum respondente optou pela rede subordinada. Conclui-se que não é possível afirmar com precisão a classificação da rede colaborativa do projeto 'De lixo a bicho' quanto a relação entre os membros, apesar de 54\% entender que a rede é autônoma, pois $1 / 4$ dos participantes não soube opinar.

A palavra articulação tem um significado muito relevante quando o assunto é rede de colaboratividade, pois diz respeito ao elo, a linha de ligação entre os pontos (nós). Para compreender se o elo de ligação é forte, apresenta-se o Quadro 3, com as respostas acerca das afirmativas colocadas.

Quadro 3. Conhecimento e articulação entre os membros.

\begin{tabular}{|l|c|c|c|c|c|}
\hline Questões & $\begin{array}{l}\text { Discordo } \\
\text { totalmente }\end{array}$ & $\begin{array}{l}\text { Discordo } \\
\text { parcialmente }\end{array}$ & $\begin{array}{l}\text { Concordo } \\
\text { parcialmente }\end{array}$ & $\begin{array}{l}\text { Concordo } \\
\text { totalmente }\end{array}$ & $\begin{array}{l}\text { Não concordo } \\
\text { etrom } \\
\text { discordo }\end{array}$ \\
\hline $\begin{array}{l}\text { Tenho pleno conhecimento de quem são os } \\
\text { demais participantes desta rede } \\
\text { colaborativa e do papel que cada um } \\
\text { desempenha no projeto 'De lixo a bicho'. }\end{array}$ & & $8,2 \%$ & $29,2 \%$ & $54,2 \%$ & $4,2 \%$ \\
\hline $\begin{array}{l}\text { Tenho pleno conhecimento de quem são os } \\
\text { participantes dessa rede colaborativa no } \\
\text { projeto 'De lixo a bicho' e me } \\
\text { articulo/relaciono diretamente com eles. }\end{array}$ & & $20,8 \%$ & $54,2 \%$ & $12,3 \%$ & $8,3 \%$ \\
\hline
\end{tabular}

Fonte: Elaborado pelas autoras (2020).

Tratando-se de uma rede colaborativa e entendendo que o trabalho em rede caracteriza-se pela formação de alianças estratégicas que angaria esforços para realizar ações conjuntas, na qual uma parte fortalece a outra, Kronemberg (2001) afirma que quanto mais forte for a relação entre os membros, mais forte essa rede será. Pode-se compreender, que o percentual apresentado, embora significativo pois, apresenta que mais de 50\%, poderia ser ainda maior, ou seja, faz-se necessário elaborar estratégias de aproximação entre os membros. Tal conclusão, afirma-se na análise das respostas acerca da segunda afirmação do quadro 3, na qual 12,3\% optaram pela alternativa 'concordo totalmente', ao passo que 54,2\% escolheram a alternativa 'concordo parcialmente'. É preciso considerar ainda, que para ambas afirmativas, 4,2\% optaram pela resposta 'discordo totalmente', ou seja, existe na rede, pessoas que além de não ter pleno conhecimento de todos os participantes, também não se relacionam com os seus pares. Embora o percentual seja baixo, não pode ser desconsiderado, pois um trabalho em rede exige articulação entre os membros.

A seguir os participantes analisaram a afirmação: 'o objetivo principal da rede colaborativa dentro do projeto 'De lixo a bicho' é o de fomentar vivências e ações de 
educação socioambiental junto à comunidade por meio da utilização de materiais lúdicos residuais'. Os resultados mostraram que aproximadamente $80 \%$ dos respondentes corroboram com a afirmação. O resultado demonstra um entendimento do objetivo central da rede.

Quadro 4. Tipologia da rede do projeto segundo participantes

\begin{tabular}{|l|c|}
\hline Tipologia de rede quanto à estrutura & Participantes \\
\hline $\begin{array}{l}\text { É uma rede fragmentada, pois há falhas estruturais resultantes da ausência ou pouca } \\
\text { ligação/interação entre os membros da rede }\end{array}$ & $8,3 \%$ \\
\hline $\begin{array}{l}\text { É uma rede densa/compacta, pois há pouca fragmentação, ou seja, a relação/ligação entre } \\
\text { os atores sociais dessa rede é forte e presente. }\end{array}$ & $34,5 \%$ \\
\hline Não sei opinar. & $54,2 \%$ \\
\hline
\end{tabular}

Fonte: Elaborado pelas autoras (2020).

O Quadro 4 mostra que os participantes, têm pouco conhecimento acerca da característica estrutural da rede, uma vez que mais da metade, 54,2\% dos respondentes não souberam opinar, mesmo que um pouco mais de 1/3 consideram a rede densa/compacta. Novamente identifica-se que existem participantes que não conseguem definir as ações da rede como um processo colaborativo, pois $8,3 \%$ optaram pela resposta 'é uma rede fragmentada. Ou seja, é preciso que a identidade de rede seja clara a todos os participantes.

A fim de completar as análises acerca da estrutura da rede do projeto 'De lixo a bicho', recorda-se o que Marcon e Moiner (2000 apud ALMEIDA, 2014) trazem acerca das configurações tipológicas de rede quanto a sua dimensão, ou seja, a rede pode ter uma dimensão hierárquica do tipo vertical; cooperativa do tipo horizontal, contratual do tipo formal e de conivência do tipo informal. O Quadro 5 traz os resultados referente à questão: 'quanto a dimensão tipológica da rede do projeto 'De lixo a bicho', você a classifica como'.

Quadro 5. Dimensão tipológica da rede do projeto 'De lixo a bicho' segundo participantes.

\begin{tabular}{|l|c|}
\hline Dimensão tipológica & Participantes \\
\hline $\begin{array}{l}\text { Vertical, pois sua dimensão é hierarquizada e esta configuração de rede é utilizada por } \\
\text { exemplo, pelas grandes redes de distribuição, que adotam a estratégia de redes verticais } \\
\text { para estar mais próxima do cliente }\end{array}$ & - \\
\hline $\begin{array}{l}\text { Horizontal, pois sua dimensão é cooperativa uma vez que esse tipo de rede é constituído } \\
\text { por empresas que guardam cada uma sua independência, mas optam por coordenar } \\
\text { atividades específicas de forma conjunta }\end{array}$ & $29,2 \%$ \\
\hline $\begin{array}{l}\text { Formal, pois sua dimensão é contratual, ou seja, refere-se a redes formalizadas por meio } \\
\text { de termos contratuais que estabelece regras de condutas entre os atores que a integram }\end{array}$ & $4,2 \%$ \\
\hline $\begin{array}{l}\text { Informal, pois sua dimensão é por conivência, ou seja, as redes de conivência permitem } \\
\text { os encontros informais entre os atores econômicos (empresas, organizações profissionais, } \\
\text { instituições, universidades, associações, dentre outros) que são portadores de } \\
\text { preocupações comuns }\end{array}$ & $33,3 \%$ \\
\hline Nenhuma das alternativas contempla a tipologia do projeto 'De lixo a bicho' & - \\
\hline Não sei opinar & $33,3 \%$ \\
\hline
\end{tabular}

Fonte: Elaborado pelas autoras (2020). 
Observa-se que os participantes, não têm uma compreensão clara da dimensão da rede, os resultados dificultam afirmar com precisão qual dimensão tipológica da rede, pois $33,3 \%$ não souberam opinar e outros $33,3 \%$ acreditam que sua dimensão seja por conivência do tipo informal. Além disso, mais de $1 / 4$ dos participantes optaram pela rede horizontal e apenas uma pessoa, que representa $4,2 \%$ do total, acredita que esta rede seja do tipo formal.

Diante do exposto e, levando em consideração o mesmo quantitativo percentual dos que não souberam opinar e dos que identificaram a rede como informal, não é possível determinar qual a classificação exata. Os dados mostram uma certa tendência à rede informal, todavia percebe-se fortemente as dificuldades de entendimento que os membros da rede possuem acerca da compreensão tipológica da rede.

Uma vez que o propósito da formação da rede está claramente definido, pressupõese que se saiba, quem serão os beneficiados e quais benefícios advém de um trabalho colaborativo. Para isso, questionou-se: 'você sabe quem são os beneficiados por essa rede colaborativa dentro do projeto 'De lixo a bicho?' A maioria dos participantes $(54,2 \%)$ afirma que 'sim, tenho pleno conhecimento de quem são os beneficiados por essa rede colaborativa'. Considerando que exatamente 1/3 dos respondentes ou 33,3\% optaram por 'conheço em parte quem são os beneficiados por essa rede colaborativa', reforça-se a importância da articulação que um trabalho em rede demanda, que por vezes, apresenta sinais de falhas no projeto 'De lixo a bicho', caso contrário o percentual dos que optaram por 'não tenho conhecimento de quem são os beneficiados por essa rede colaborativa seria igual a zero, porém foi $12,5 \%$.

Identificou-se a compreensão dos membros quanto ao foco de atuação da rede, que em suma, complementa os dados apresentados anteriormente. Pois, tão importante quanto saber aonde se quer chegar (objetivo da rede), quanto quem são seus beneficiados, é saber qual o campo de atuação da rede. Aproximadamente $80 \%$ dos respondentes, têm a compreensão de que esta rede assume um compromisso social (pois nascem e se sustentam de uma visão comum sobre a sociedade ou sobre determinada questão, além de demandar estratégias de mobilização constante das parcerias). Tal compreensão corrobora com o que se tem levantado até aqui, ou seja, a importância em demandar ações estratégicas por meio de parcerias. Porém foi significativo os que não sabem opinar $(16,7 \%)$.

Por fim, restou saber, quais os benefícios em participar de uma rede colaborativa, pois assim, é possível compreender quais são as causas motivadoras que impulsionam seus 
membros a fomentar suas ações de maneira colaborativa. Para isso, apresentou-se a questão: 'você identifica algum benefício (qualquer aspecto positivo quantificável obtido no processo de colaboração) que sua participação nesse projeto lhe proporcionou? Descreva quais:' As respostas foram desde a conscientização das questões socioambientais e sustentáveis como o reaproveitamento de resíduos, a divulgação da marca da empresa, conhecimento acerca das redes colaborativas, articulação com a comunidade, a aprendizagem que se dá por meio do lúdico (utilização dos jogos), entre outras. Logo, compreende-se quão importante e impactante é a realização de um trabalho colaborativo.

\section{Considerações finais}

Os resultados apontaram que o trabalho colaborativo, em forma de rede, no projeto 'De lixo a bicho' contribui para um desenvolvimento local mais sustentável, segundo os participantes $(79,2 \%)$.

Quanto à tipologia de relação entre os membros da rede, na opinião dos respondentes, é uma rede autônoma, ou seja, a rede é aberta e trabalha por pactuação, constrói-se uma identidade de rede onde o controle é compartilhado, porém o percentual sugere cautela na proposição definitiva. Quanto a sua característica estrutural, é preciso considerar que embora $34,5 \%$ dos respondentes entendam que esta é uma rede densa/compacta, pois há pouca fragmentação entre os atores sociais envolvidos, mais da metade não soube opinar. Quanto à dimensão da rede, 33,3\% dos participantes compreendem esta rede como uma rede informal. No que tange o conhecimento mútuo e articulação entre os membros, pergunta fundamental para chegar ao objetivo específico, nota-se que $54,2 \%$ dos participantes afirmaram ter pleno conhecimento de quem são os participantes desta rede colaborativa no projeto 'De lixo a bicho' e que há uma articulação/relação direta entre eles. Em relação ao foco de atuação, a maioria classifica a rede como uma rede de compromisso social e também conhecem o objetivo principal da rede colaborativa do projeto 'De lixo a bicho': fomentar vivências, ações de educação socioambiental junto à comunidade por meio da utilização de materiais lúdicos confeccionados com resíduos.

A partir dos conceitos estudados e análises apresentadas percebeu-se que a relação contínua das conexões exige que os membros tenham mais proximidade, e que os objetivos sejam claramente definidos para que seja possível não somente criar uma identidade de rede, mas sobretudo torná-la forte. A partir dessa reflexão sugerem-se reuniões periódicas 
com o maior número possível de participantes, para socialização das atividades realizadas, troca de experiências, visualização e sistematização de melhorias futuras.

Os resultados apresentam a fragilidade com relação a participação e ao planejamento, mostrando que os respondentes não se sentem totalmente partícipes desses momentos, sugere-se a participação dos atores em todas as etapas do projeto, bem como momentos/encontros formativos, com foco não somente nas questões socioambientais, mas também na importância do trabalho em formato de redes de colaboratividade.

O IFSC, enquanto instituição de ensino, tem a responsabilidade de ser um elo propulsor de ações colaborativas envolvendo diferentes atores. Apesar das dificuldades operacionais do trabalho em rede, as ações são mais efetivas e duradouras, pois o fazer educação ambiental ocorre em todas as etapas do e não somente nas atividades fins.

Há necessidade de constantes avaliações do trabalho colaborativo em rede do IFSC e de seus parceiros, seja nos aspectos estruturais da rede, seja nos aspectos pedagógicos das propostas de educação ambiental ou nos impactos socioambientais causados pelo projeto 'De lixo a bicho'. As avaliações constantes do trabalho colaborativo em rede permitem uma maior identificação das fragilidades existentes, como por exemplo, a dificuldade de compreensão tipológica e estrutural da rede pelos membros que a compõem ou a participação de empresas parceiras somente como doadora de resíduos. De igual modo, as potencialidades do projeto, tais como a aprendizagem lúdica, as parcerias existentes, e a educação socioambiental, podem ancorar o fomento de mais ações colaborativas sustentáveis em rede. Em suma, o projeto permite a abertura para uma reflexão que não se encerra por si só, uma vez que, converge para fomento e fortalecimento de práticas sustentáveis que ultrapassam o ambiente escolar e o contex to social local.

\section{Referências}

ALMEIDA, Onília Cristina de Souza de. Redes interorganizacionais: revisão bibliográfica de 2000 a 2013. In: International Conference on Engineering and Technology Education, 13. 2014, Guimarães, Portugal. Anais [...] Guimarães, Portugal, 2014. Disponível em: http://copec.eu/congresses/intertech2014/proc/works/44.pdf. Acesso em: 24 abr. 2020.

BARBIERI, José Carlos; SILVA Dirceu da. Desenvolvimento sustentável e educação ambiental: uma trajetória comum com muitos desafios. RAM, Rev. Adm. Mackenzie (Online).vol.12, no.3. São Paulo: June, 2011. Disponível em: https://www.scielo.br/scielo.php?script=sci_arttext\&pid=S1678-69712011000300004. Acesso em: 22 out. 2020.

CASTRO, Mary Lobas de; CANHEDO JR, Sidnei Garcia. Educação ambiental como 
instrumento de participação. In: PHILIPPI, Arlindo Jr.; PELICIONI, Maria Cecília Focesi (org.). Educação ambiental e sustentabilidade. Barueri, SP: Manole, 2005.

COOPER, Donald R.; SCHINDLER, Pamela S. Métodos de pesquisa em administração. Porto Alegre: AMGH, 2016.

CUNHA, Julio Araujo Carneiro da; PASSADOR, João Luiz; PASSADOR, Cláudia Souza. Recomendações e apontamentos para categorizações em pesquisas sobre redes interorganizacionais. Cad. EBAPE.BR, Rio de Janeiro, v. 9, n. spe1, p. 505-529, jul. 2011. Disponível em: http://www.scielo.br/scielo.php?script=sci_arttext\&pid=S167939512011000600005\&lng=en\&nrm=iso. Acesso em: 24 abr. 2020.

DIAS, Reinaldo. Gestão ambiental: responsabilidade social e sustentabilidade. 2. ed., rev. e atual. São Paulo: Atlas, 2011.

FERNANDES, Karina Ribeiro. Constituição de redes organizacionais como nova forma das organizações do terceiro setor. [S.1.], 2008. Disponível em: http://www.aedmoodle.ufpa.br/pluginfile.php/126023/mod_book/chapter/2003/REDES\%2 0ORGANIZACIONAIS.pdf. Acesso em: 24 abr. 2020

GIL, Antonio Carlos. Como elaborar projetos de pesquisa. 6. ed. São Paulo: Atlas, 2017.

INOJOSA, Rose Marie. Redes de compromisso social. Revista de Administração Pública, v. 33 n. 5, 1999. Disponível em:

http://bibliotecadigital.fgv.br/ojs/index.php/rap/article/view/7628. Acesso em: 24 abr. 2020.

KRONEMBERGER, Denise. Desenvolvimento local sustentável: uma abordagem prática. São Paulo: Senac São Paulo, 2011.

LIMA, C. S. M.; et al. Projeto "De Lixo a Bicho": extensão voltada à Educação, Inovação e à Sustentabilidade. In: Anais 37 SEURS - Meio Ambiente. 2019. Disponível em: https://repositorio.ufsc.br/handle/123456789/199210. Acesso em: 14 abr. 2020.

MAGOZO, Helena Maria Campos. Subjetividade no processo educativo: contribuições da psicologia a educação ambiental. In: PHILIPPI, Arlindo Jr.; PELICIONI, Maria Cecília Focesi (org.). Educação ambiental e sustentabilidade. Barueri, SP: Manole, 2005.

MARCONI, Marina de Andrade; LAKATOS, Eva Maria. Fundamentos de metodologia científica. 8. ed. São Paulo: Atlas, 2017

MARINHO, Cássio. Redes: uma introdução às dinâmicas da conectividade e da autorealização. Brasília: WWF.Brasil,2003

MARIANO, Enzo Barberio; GUERRINO, Fabio Muller; REBELATTO, Daisy Aparecida do Nascimento. Análise da relação entre estrutura e desempenho de redes interorganizacionais colaborativas. Gest. Prod., São Carlos, v. 19, n. 3, p. 471-479, 2012. Disponível em: http://www.scielo.br/pdf/gp/v19n3/03.pdf . Acesso em: 7 out. 2019.

MANO, Eloisa Baisotto; PACHECO, Élen Beatriz Acordi Vasques; BONELLI, Cláudia Maria Chagas. Meio ambiente, poluição e reciclagem. 1. ed. São Paulo: Edgard Blucher, 
2005.

MATTOS, Neide Simões de; GRANATO, Suzana Facchini. Lixo: problema nosso de cada dia: cidadania, reciclagem e uso sustentável. São Paulo: Saraiva, 2005.

NAVARRO, Amanda; SAMPAIO, Michelle. Redes colaborativas em prol do desenvolvimento Sustentável. In: Congresso Nacional de Excelência em Gestão, 12., 2012, Rio de Janeiro, RJ. Anais [...] Rio de Janeiro, RJ, 2012.

OLIVEIRA, Maria Marly de. Como fazer projetos, relatórios, monografias, dissertações e teses. 5. ed. Rio de Janeiro: Elsevier, 2011.

OLIVIERI, Laura. A importância histórico-social das Redes. Jan. 2003. Studylib. Disponível em: https://studylibpt.com/doc/1823032/a-import\%C3\%A2nciahist\%C3\%B3rico-social-das-redes\%3F. Acesso em: 24 abr. 2020.

PEIXE, Rita Inês Petrykowski. A importância das redes colaborativas em ações extensionistas. In: Seminário de Extensão Universitária da Região Sul, 34., 2016, Camboriú, SC. Anais [...] Camboriú, SC, 2016. Disponível em: https://drive.google.com/file/d/1_80VNThlvshsRjg8x5BS_H2HkVgiqsP4/view. Acesso em: 24 abr. 2020.

PEREIRA, Carla Sofia Gonçalves. A organização da informação e conhecimento em redes colaborativas como um processo de construção social do significado: uma teoria e um método prático. 2010. Tese (Doutorado em Engenharia Informática) - Faculdade de Engenharia, Universidade do Porto, Porto, 2010. Disponível em: https://repositorioaberto.up.pt/bitstream/10216/59548/1/000140070.pdf. Acesso em: 24 abr. 2020.

PELICIONI, Maria Cecília Focesi; PHILIPPI JR, Arlindo. Educação ambiental e sustentabilidade. Barueri, SP: Manole, 2005.

RUDIO, Franz Victor. Introdução ao projeto de pesquisa científica. 43. ed. Petrópolis, RJ: Vozes, 2015.

SOUZA, Antônio Carlos de; FIALHO, Francisco; OTANI, Nilo. TCC: métodos e técnicas. Florianópolis: Visual Books, 2007. 